\title{
PENGARUH KAPUR PADA MEDIA TANAM TERHADAP PERTANAMAN CABAI MERAH
}

\section{The Effect of Lime of Planting Media on Red Chili Planting}

\author{
Eni Miftahul Janah ${ }^{1}$, Idwar $^{2}$, Armaini $^{2}$ \\ ${ }^{1)}$ Mahasiswa Jurusan Agroteknologi, Fakultas Pertanian, Universitas Riau \\ ${ }^{2)}$ Dosen jurusan Agroteknologi, Fakultas Pertanian, Universitas Riau \\ Department Agrotechnology, Faculty of Agriculture, Riau University \\ Email: miftahuljanaheni@gmail.com/085274361779
}

[Diterima: Januari 2020; Disetujui: April 2020]

\begin{abstract}
Red chili has a potential to be developed in sub-optimal land (Inceptisol, Ultisol, and peatland) by adding lime as amelioration. Besides that good characteristics of peat soils can also improve Ultisol and Inceptisol soils when is mixed. With the application of these technologies can increase the productivity of red chili. This study aimed to examine the effect of agricultural lime on several growing media and to determine the best treatment on the growth and yield of red chili. The study was conducted at the experimental farm of the Faculty of Agriculture, University of Riau from April to September 2018. The research was carried out in factorial with 2 factors and designed by completey randomized design and then tested with Duncan's new multiple range test. The first factor was media Ultisol, Inceptisol, peat, peat+Ultisol, and peat+Inceptisol. The second factor consisted of lime $0,0 \mathrm{x}$ Al-dd, 1,0 x Al-dd and 2,0 x Al-dd. The observed parameters were stem diameter, flowerage, number, length, diameter, and weight. The results showed that lime application 1,0 x Al-dd for Inceptisol provided a good effect on stem diameter, flowerage, number, length, diameter, and fruit weight. The best treatment was found in 1,0 x Al-dd on peat+Inceptisol with a productivity of 135,10 per plant.
\end{abstract}

Keywords: Lime, Planting media, Chili, Ultisol, Inceptisol, Peat,

\begin{abstract}
ABSTRAK
Cabai merah potensial dikembangkan di lahan sub optimal (Inceptisol, Ultisol dan gambut) dengan memberikan kapur sebagai bahan amelioran. Selain itu karakteristik yang baik dari tanah gambut juga dapat membenah tanah Ultisol dan Inceptisol bila dicampur. Dengan penerapan teknologi tersebut diharapkan dapat meningkatkan produktivitas dari cabai merah. Penelitian bertujuan mengetahui pengaruh kapur kapur pada media tanam serta menentukan perlakuan terbaik terhadap pertumbuhan dan daya hasil tanaman cabai merah. Penelitian dilaksanakan di Kebun Percobaan Fakultas Pertanian Universitas Riau bulan April sampai September 2018, dilaksanakan secara faktorial 2 faktor disusun menurut Rancangan Acak Lengkap dengan uji lanjut Duncan's New Muttiple Range Test. Faktor pertama tanah Ultisol, Inceptisol, gambut, gambut+Ultisol dan gambut+Inceptisol. Faktor kedua pemberian kapur 0,0 x Al-dd, 1,0 x Al-dd, dan 2,0 x Al-dd. Parameter yang diamati tinggi dikotomus, diameter batang, umur berbunga, jumlah, panjang, diameter dan berat buah. Hasil penelitian menunjukkan pemberian kapur 1,0 x Al-dd pada Inceptisol berpengaruh baik terhadap diameter batang, umur muncul bunga, jumlah buah, panjang buah, diameter buah dan berat buah. Perlakuan yang tebaik terdapat pada 1,0 x Al-dd pada gambut+Inceptisol menghasilkan produktivitas sebesar 135,10 g per tanaman.
\end{abstract}

Kata Kunci: Kapur, Medi tanam, Cabai, Ultisol, Inceptisol, Gambut,

\section{PENDAHULUAN}

Cabai merah (Capsicum annuum L.) merupakan tanaman hortikultura yang diminati oleh sebagian masyarakat Indonesia. Pengembangan tanaman cabai di Indonesia belum mencapai optimal. Hal ini ditandai dengan berkurangnya luas areal tanam, Badan Pusat Statistik (2017) menyatakan produksi cabai merah di Riau tahun 2015 sebesar 7.393 ton dengan luas panen 1.775 ha atau produktivitas 4,17 ton.ha ${ }^{-1}$ Produksi cabai 
merah di Riau meningkat pada tahun 2016 yaitu 12.002 ton dengan luas panen 1.742 ha atau produktivitasnya 6,89 ton.ha ${ }^{-1}$. Berdasarkan data tersebut terlihat bahwa terjadi peningkatan produktivitas cabai di Riau mencapai 65,22\%. Menurut Wiryanta (2011), produktivitas 6,89 ton.ha ${ }^{-1}$ masih rendah dibandingkan dengan potensi cabai yang dapat mencapai produktivitas 20 ton.ha ${ }^{-1}$.

Faktor yang menyebabkan rendahnya produktivitas cabai adalah kondisi lahan yang kurang optimal bagi pertumbuhan dan perkembangan tanaman cabai. Lahan di Provinsi Riau sebagian merupakan tanah marginal. Tanah marginal (tanah sub optimal) potensial untuk pertanian, tetapi secara alami kesuburan tanah marginal ini tergolong rendah yang ditunjukkan oleh kemasaman tinggi, ketersediaan hara rendah, kejenuhan dan basabasa dapat dipertukarkan rendah, didominasi tanah Inceptisol, Ultisol dan gambut (Suharta, 2010). Perbaikan tanah marginal yang tepat di antaranya menggunakan bahan pembenah keasaman tanah, perbaikan kondisi kesuburan tanah, baik melalui pengapuran ataupun memanfaatkan gambut sebagai bahan organik untuk tanah mineral dan mengurangi dampak negatif gambut melalui penambahan tanah mineral.

Pengapuran bertujuan untuk membenah tanah dalam meningkatkan $\mathrm{pH}$ dari $\mathrm{pH}$ masam menjadi $\mathrm{pH}$ agak masam dan netral. pemberian kapur dengan 1,0 x Al-dd dapat menaikkan $\mathrm{pH}$ dari 4,5 - 5,0 menjadi 5,3 - 5,4. Pemberian kapur setara 2,0 x Al-dd dapat menaikkan $\mathrm{pH}$ hingga 5,9-6,0. Perbaikan tanah marginal juga dapat dilakukan dengan pencampuran tanah mineral tersebut (Inceptisol dan Ultisol) dengan tanah gambut dan sebaliknya (Damanik et al. 2010).
Penelitian ini bertujuan mengetahui pengaruh pemberian kapur pada media tanam terhadap pertumbuhan dan daya hasil serta menentukan perlakuan terbaik untuk pertumbuhan dan daya hasil tanaman cabai merah.

\section{METODOLOGI}

Penelitian dilaksanakan di Kebun Percobaan Fakultas Pertanian Universitas Riau mulai bulan April sampai September 2018. Bahan yang digunakan benih cabai merah Varietas Lado F1, air, tanah Inceptisol, Ultisol, gambut, pupuk kandang, NPK, kapur $\mathrm{CaCO}_{3}$, dithane M-45 $70 \mathrm{WP}$, curacron $500 \mathrm{EC}$. Alat yang digunakan cangkul, ayakan ukuran 20 mesh, baki semai, hand sprayer, polybag, gembor, mistar, timbangan analitik, corong, gelas ukur, tabung plastik, tabung reaksi. Penelitian dilaksanakan secara faktorial terdiri 2 faktor disusun menurut RAL Faktor pertama tanah Ultisol, Inceptisol, gambut, gambut+Ultisol, gambut+Inceptisol. Faktor kedua tanpa kapur $(0,0 \times \mathrm{Al}$-dd), Pemberian kapur 1,0 x Al-dd, kapur 2,0 x Al-dd. sehingga didapat 15 kombinasi perlakuan, masing-masing perlakuan diulang 3 kali sehingga diperoleh 45 unit percobaan. Setiap unit percobaan terdiri dari 2 tanaman sehingga didapat 90 tanaman yang diamati. Parameter yang diamati ialah tinggi dikotomus, diameter batang, umur berbunga, jumlah buah, panjang buah, diameter buah dan berat buah.

\section{HASIL DAN PEMBAHASAN}

\section{Pertumbuhan dan Daya Hasil Tanaman Tinggi dikotomus}

Hasil pengamatan tinggi dikotomus tanaman cabai dapat dilihat pada Tabel 1 .

Tabel 1. Rerata tinggi dikotomus cabai merah $(\mathrm{cm})$ pada perlakuan pemberian kapur dan berbagai media tanam

\begin{tabular}{|c|c|c|c|c|}
\hline \multirow{2}{*}{ Media Tanam } & \multicolumn{3}{|c|}{$\begin{array}{c}\text { Pemberian Kapur pada Medium Kriteria Masam- } \\
\text { Agak Masam }\end{array}$} & \multirow[b]{2}{*}{ Rerata } \\
\hline & $\begin{array}{l}0,0 \times \mathrm{Al}-\mathrm{dd} \\
\text { (Kontrol) }\end{array}$ & $1,0 \times \mathrm{Al}-\mathrm{dd}$ & $2,0 \times \mathrm{Al}-\mathrm{dd}$ & \\
\hline Ultisol & $20,58 \mathrm{~h}$ & $21,67 \mathrm{fgh}$ & $21,00 \mathrm{gh}$ & $21,08 \mathrm{~b}$ \\
\hline Inceptisol & $23,50 \mathrm{def}$ & $27,50 \mathrm{a}$ & $26,50 \mathrm{~b}$ & $25,83 \mathrm{a}$ \\
\hline Gambut & $24,67 \mathrm{~cd}$ & $26,00 \mathrm{abc}$ & $26,33 \mathrm{ab}$ & $25,67 \mathrm{a}$ \\
\hline Gambut+Ultisol & 22,67 ef & $22,75 \mathrm{efg}$ & 22,08 efg & $22,50 \mathrm{~b}$ \\
\hline Gambut+Inceptisol & $23,83 \mathrm{de}$ & 24,33 cde & $25,33 \mathrm{bcd}$ & $24,50 \mathrm{a}$ \\
\hline Rerata & $23,05 \mathrm{~b}$ & $24,45 \mathrm{a}$ & $24,25 \mathrm{a}$ & \\
\hline
\end{tabular}

Angka-angka pada baris dan kolom yang diikuti huruf kecil yang sama berbeda tidak nyata menurut uji Duncan pada taraf 5 $\%$. 
Tabel 1 menunjukkan bahwa pemberian kapur 1,0 x Al-dd pada tanah Inceptisol menghasilkan tinggi dikotomus nyata lebih tinggi dari perlakuan lainnya, berbeda tidak nyata dengan kapur 1,0 x Al-dd dan 2,0 x Aldd pada tanah gambut. Hal ini karena pemberian 1,0 x Al-dd pada tanah Inceptisol mampu menaikkan $\mathrm{pH}$ tanah dari 4,15 hingga 5,92 dan mendekati netral sehingga unsur hara $P$ tercukupi sebagai sumber energi dalam bentuk ATP pada proses fotosintesi sehingga fotosintat meningkat untuk pertumbuhan tanaman dan sebagian disimpan pada organ tanaman. Lakitan (2011) meningkatnya jumlah unsur hara yang dapat diserap tanaman secara tidak langsung akan meningkatkan proses fotosintesis yang akan menghasilkan fotosintat.

Pada media tanam tanah Inceptisol menghasilkan dikotomus nyata lebih tinggi dibandingkan perlakuan lainnya, berbeda tidak nyata dengan tanah gambut dan gambut+Inceptisol. Hal ini karena tanah Inceptisol, gambut dan gambut+Inceptisol kandungan bahan organiknya tinggi karena gambut adalah kumpulan bahan organik, sedangkan Inceptisol yang digunakan juga mengandung bahan organik. Unsur hara $\mathrm{P}$ cukup tinggi direspon tanaman dalam bentuk penyerapan unsur hara lebih banyak, sehingga usur hara yang dibutuhkan tanaman tercukupi meskipun gambut $\mathrm{P}$ tersedia sangat rendah, hanya $\mathrm{P}$ total tinggi dan selama penggunaan diduga terjadi perubahan ketersediaan $\mathrm{P}$. P dapat mempercepat perkembangan akar, respirasi, pembelahan sel sehingga mendorong laju pertumbuhan vegetatif. Rosmarkam dan Yuwono (2002) P dapat mendorong pertumbuhan akar sehingga serapan hara optimal maka pertumbuhan tanaman menjadi baik.

Penambahan kapur $1,0 \quad$ x $\quad$ Al-dd menunjukkan pertumbuhan dikotomus lebih tinggi berbeda nyata dengan $0,0 \mathrm{x}$ Al-dd dengan capaian hanya $23,05 \mathrm{~cm}$. Hal ini karena kapur 1,0 x Al-dd dan 2,0 x Al-dd merupakan dosis yang sesuai untuk meningkatkan $\mathrm{pH}$, sehingga memperbaiki ketersedian hara dan sifat fisik seperti struktur tanah yang gembur, sehingga tanah yang gembur akan memudahkan akar tanaman menyerap unsur hara. Proses fisiologis tanaman akan berjalan lancar. Menurut Buckman dan Brady (1964) pemberian kapur pada tanah masam akan merangsang pembentukan struktur remah, mempengaruhi pelapukan bahan organik dan pembentukan humus.

\section{Diameter batang}

Hasil pengamatan diameter batang tanaman cabai dapat dilihat pada Tabel 2 .

Tabel 2. Rerata diameter batang cabai merah $(\mathrm{mm})$ pada perlakuan pemberian kapur dan berbagai media tanam

\begin{tabular}{|c|c|c|c|c|}
\hline \multirow[b]{2}{*}{ Media Tanam } & \multicolumn{3}{|c|}{$\begin{array}{c}\text { Pemberian Kapur pada Medium Kriteria Masam- } \\
\text { Agak Masam }\end{array}$} & \multirow[b]{2}{*}{ Rerata } \\
\hline & $\begin{array}{l}0,0 \times \text { Al-dd } \\
\text { (Kontrol) }\end{array}$ & $1,0 \times$ Al-dd & $2,0 \times \mathrm{Al}-\mathrm{dd}$ & \\
\hline Ultisol & $16,97 \mathrm{e}$ & $17,73 \mathrm{de}$ & $17,73 \mathrm{de}$ & $17,55 \mathrm{c}$ \\
\hline Inceptisol & $19,22 \mathrm{bcd}$ & $16,67 \mathrm{e}$ & $20,78 \mathrm{ab}$ & $20,89 \mathrm{a}$ \\
\hline Gambut & $19,23 \mathrm{bc}$ & $21,23 \mathrm{a}$ & $20,23 \mathrm{bc}$ & $20,23 \mathrm{ab}$ \\
\hline Gambut+Ultisol & 18,35 cde & $20,73 \mathrm{ab}$ & $18,52 \mathrm{cde}$ & $19,20 \mathrm{~b}$ \\
\hline Gambut+Inceptisol & $19,22 \mathrm{bcd}$ & $20,71 \mathrm{ab}$ & $20,69 \mathrm{ab}$ & $20,18 a b$ \\
\hline Rerata & $18,58 \mathrm{c}$ & $20,66 \mathrm{a}$ & $19,59 \mathrm{~b}$ & \\
\hline
\end{tabular}

Tabel 2 menunjukkan bahwa pemberian kapur $1,0 \mathrm{x}$ Al-dd pada tanah gambut, menghasilkan diameter batang nyata lebih tinggi dari perlakuan lainnya, berbeda tidak nyata dengan kapur 1,0 x Al-dd pada tanah gambut+Ultisol dan gambut+Inceptisol, serta kapur 2,0 x Al-dd pada tanah Inceptisol dan tanah gambut+Inceptisol. Hal ini karena kapur 1,0 $\mathrm{X}$ Al-dd pada gambut telah mencukupi ketersediaan unsur hara $\mathrm{N}$ dan $\mathrm{P}$ sehingga mempengaruhi proses pertumbuhan tanaman pada fase vegetatif. Unsur hara $\mathrm{N}$ sangat dibutuhkan dalam proses pembelahan sel, pemanjangan sel, pembentukkan klorofil dan sintesis protein pada tanaman, sedangkan unsur hara $\mathrm{P}$ dibutuhkan sebagai sumber energi 
dalam bentuk ATP pada proses fotosintesis, sehingga fotosintat yang dihasilkan meningkat dan disimpan dalam organ tanaman. Marschner (1995) fotosintat hasil fotosintesis akan digunakan oleh tanaman untuk pembentukan organ tanaman.

Medium tanam (Tabel 2) menunjukkan bahwa Inceptisol menghasilkan diameter batang nyata lebih tinggi dari perlakuan Ultisol, gambut+Ultisol dan berbeda tidak nyata dengan tanah gambut dan gambut+Inceptisol. Hal ini karena tanah Inceptisol dan gambut+Inceptisol memiliki nilai $\mathrm{pH}$ yang lebih mendekati netral dibandingkan dengan tanah Ultisol dan gambut+Ultisol. Gambut berasal dari bahan organik dengan tingkat kandungan bahan organik tinggi. Berdasarkan analisis unsur Ptersedia, tanah Inceptisol memiliki ketersediaan unsur $\mathrm{P}$ cukup tinggi dibandingkan medium tanah yang lain yaitu dengan capaian 90,77 ppm yang tergolong sangat tinggi sehingga hara yang dibutuhkan tanaman menjadi tercukupi untuk menghasilkan fotosintat secara optimal sebagai sumber energi dan bahan untuk membentuk senyawa lain yang dibutuhkan tanaman sebagai cadangan makanan pada organ

Tabel 3. Rerata umur muncul bunga pertama (HST) pada perlakuan pemberian kapur dan berbagai media tanam

\begin{tabular}{lllll}
\hline \multirow{2}{*}{ Media Tanam } & \multicolumn{2}{c}{ Pemberian Kapur pada Medium Kriteria Masam- } \\
& \multicolumn{3}{c}{ Agak Masam } & \multirow{2}{*}{ Rerata } \\
\cline { 2 - 4 } & $\begin{array}{l}0,0 \times \mathrm{Al}-\mathrm{dd} \\
\text { Kontrol) }\end{array}$ & $1,0 \times \mathrm{Al}$-dd & $2,0 \times \mathrm{Al}-\mathrm{dd}$ & \\
\hline Ultisol & $60,67 \mathrm{ab}$ & $61,33 \mathrm{ab}$ & $60,50 \mathrm{ab}$ & $60,83 \mathrm{ab}$ \\
Inceptisol & $61,00 \mathrm{~b}$ & $60,83 \mathrm{ab}$ & $61,67 \mathrm{~b}$ & $61,50 \mathrm{~b}$ \\
Gambut & $61,33 \mathrm{ab}$ & $61,00 \mathrm{ab}$ & $61,67 \mathrm{~b}$ & $61,33 \mathrm{~b}$ \\
Gambut+Ultisol & $60,83 \mathrm{ab}$ & $62,00 \mathrm{~b}$ & $61,67 \mathrm{~b}$ & $61,50 \mathrm{~b}$ \\
Gambut+Inceptisol & $59,67 \mathrm{a}$ & $60,17 \mathrm{ab}$ & $60,83 \mathrm{ab}$ & $60,22 \mathrm{a}$ \\
\hline Rerata & $60,90 \mathrm{a}$ & $61,07 \mathrm{a}$ & $61,27 \mathrm{a}$ & \\
\hline
\end{tabular}

Angka-angka pada baris dan kolom yang diikuti huruf kecil yang sama berbeda tidak nyata menurut uji DNMRT pada taraf $5 \%$.

Tabel 3 menunjukkan bahwa kapur 0,0 $x$ Al-dd pada tanah gambut+Inceptisol menghasilkan lebih cepat muncul bunga, hanya berbeda nyata dengan perlakuan $0,0 \times \mathrm{Al}$-dd pada tanah Inceptisol dan kapur 1,0 x Al-dd pada tanah gambut+Ultisol serta kapur 2,0 x Al-dd pada tanah Inceptisol, gambut, tanah gambut+Ultisol. Hal ini karena campuran gambut+Inceptisol merupakan suatu perbaikan kondisi tanah karena tanah gambut mempunyai permasalahan tanah yaitu $\mathrm{pH}$ rendah. Sifat kimia tanah yang lebih baik mampu tanaman seperti akar, batang, buah dan biji. Safuan dan Bahrun (2012) pertumbuhan dan produksi tanaman ditentukan oleh fotosintesis yang dikendalikan unsur hara.

Pemberian kapur $1,0 \quad \mathrm{x}$ Al-dd menghasilkan diameter batang lebih besar berbeda nyata dengan perlakuan lainnya, dengan capaian 20,66 $\mathrm{mm}$. Hal ini karena kapur 1,0 x Al-dd sudah mampu memperbaiki sifat kimia tanah seperti $\mathrm{pH}$ dan ketersediaan hara $\mathrm{P}$ menjadi lebih baik, sehingga pertumbuhan vegetatif berjalan dengan optimal yang diindikasikan dengan semakin besarnya diameter batang yang diperoleh, namun jika diberikan kapur 2,0 x Al-dd unsur hara di dalam tanah akan menurun karena ketersediaan menjadi fosfat berkurang dan kalsium yang tidak larut maka pertumbuhan diameter batang menjadi kurang baik. Sutedjo dan Kartasapoetra (2002) pemberian kapur yang berlebihan pada tanah mengakibatkan tanaman kerdil, Mn dan P menjadi tidak tersedia.

\section{Umur muncul bunga pertama}

Hasil pengamatan umur muncul bunga pertama tanaman cabai dapat dilihat pada Tabel 3. menyediakan unsur hara esensial seperti Ptersedia dengan capaian $60,58 \mathrm{ppm}$. $\mathrm{P}$ berperan dalam proses pembentukan bunga pada tanaman, hal ini berkaitan dengan proses metabolisme tanaman dalam keberlangsungan fotosintesis menghasilkan fotosintat dalam bentuk karbohidrat akan ditranslokasi ke seluruh bagian tanaman dan akumulasi karbohidrat pada bagian tajuk pada masa vegetatif akhir dapat memacu pembungaan. Poerwanto (2003) P sebagai penyusun karbohidrat dan asam amino merupakan faktor 
internal yang mempengaruhi induksi pembungaan pada tanaman.

Pada media tanam tanah
gambut+Inceptisol menunjukkan umur muncul bunga pertama lebih cepat dibandingkan dengan tanah lainnya, berbeda tidak nyata dengan perlakuan tanah Ultisol. Hal ini karenakan pada tanah gambut+Inceptisol mampu menyediakan unsur $\mathrm{P}$ untuk tanaman cabai, dimana unsur hara yang diperlukan dalam proses pembungaan memiliki unsur $\mathrm{P}$ yang dibutuhkan oleh tanaman pada fase generatif. Pertumbuhan fase vegetatif tanaman berakhir dengan keluarnya bunga yang disebut fase generatif, pada tahap ini tanaman mulai mengalokasikan hasil asimilatnya untuk bunga yang akan menjadi buah. Unsur P berperan dalam reaksi pada fase gelap fotosintesis, respirasi dan berbagai proses metabolisme lainnya. Sunarto (2002) unsur P berfungsi sebagai zat pembangun yang terikat dalam bentuk senyawa organik yang terdapat tubuh tanaman yang berhubungan dengan perkembangan generatif seperti bunga.

Pemberian kapur mempercepat umur berbunga yang berbeda tidak nyata, semua perlakuan $(0,0 \times \mathrm{Al}-\mathrm{dd}, 1,0 \times \mathrm{Al}-\mathrm{dd}, 2,0 \mathrm{x} \mathrm{Al}-$ dd). Hal ini karena ketersediaan hara dalam tanah telah menyediakan unsur hara $\mathrm{P}$ yang dapat mempercepat umur muncul bunga. Ketersediaan unsur hara selama proses pertumbuhan vegetatif hingga menuju fase generatif sangat menentukan keberhasilan proses pembentukan bunga. Dobermann dan Fairhurst (2000) fungsi $\mathrm{P}$ sebagai cadangan energi dan penyusun senyawa untuk merubah giener, untuk membran sel dan fosfoprotein.

\section{Jumlah buah per tanaman}

Hasil pengamatan jumlah buah per tanaman cabai dapat dilihat pada Tabel 4 .

Tabel 4. Rerata jumlah buah per tanaman cabai merah pada perlakuan pemberian kapur dan berbagai media tanam

\begin{tabular}{lllll}
\hline \multirow{2}{*}{ Media Tanam } & \multicolumn{3}{c}{ Pemberian Kapur pada Medium Kriteria Masam- } \\
\cline { 2 - 4 } & \multicolumn{3}{c}{ Agak Masam } & \multirow{2}{*}{ Rerata } \\
\cline { 2 - 4 } & $\begin{array}{l}\text { 0,0 x Al-dd } \\
\text { (Kontrol) }\end{array}$ & $1,0 \times$ Al-dd & $2,0 \times$ Al-dd & \\
\hline Ultisol & $31,83 \mathrm{f}$ & $34,67 \mathrm{bcd}$ & $33,33 \mathrm{def}$ & $33,28 \mathrm{~b}$ \\
Inceptisol & $35,67 \mathrm{bcd}$ & $39,50 \mathrm{a}$ & $37,67 \mathrm{ab}$ & $37,61 \mathrm{a}$ \\
Gambut & $34,83 \mathrm{bcd}$ & $37,33 \mathrm{abc}$ & $36,00 \mathrm{abc}$ & $36,06 \mathrm{a}$ \\
Gambut+Ultisol & $32,83 \mathrm{ef}$ & $35,00 \mathrm{bc}$ & $34,00 \mathrm{~cd}$ & $33,94 \mathrm{~b}$ \\
Gambut+Inceptisol & $35,17 \mathrm{bc}$ & $38,33 \mathrm{ab}$ & $37,00 \mathrm{ab}$ & $36,83 \mathrm{a}$ \\
\hline Rerata & $34,07 \mathrm{~b}$ & $36,97 \mathrm{a}$ & $35,60 \mathrm{a}$ & \\
\hline
\end{tabular}

Angka-angka pada baris dan kolom yang diikuti huruf kecil yang sama berbeda tidak nyata menurut uji DNMRT pada taraf $5 \%$.

Tabel 4 menunjukkan bahwa pemberian kapur 1,0 x Al-dd pada tanah Inceptisol menghasilkan nyata lebih baik pengaruhnya terhadap jumlah buah cabai per tanaman, berbeda tidak nyata dengan pemberian kapur $1,0 \mathrm{x}$ Al-dd pada tanah gambut dan gambut+Inceptisol serta kapur 2,0 x Al-dd pada Inceptisol, gambut dan gambut+Inceptisol. Hal ini karena unsur hara $\mathrm{P}$ yang tersedia dari kapur 1,0 x Al-dd pada tanah Inceptisol dapat memperbaiki kesuburan tanah serta meningkatkan ketersediaan unsur hara termasuk kandungan $\mathrm{P}$ yang akan dimanfaatkan sebagai sumber energi dalam bentuk ATP yang berdampak pada jumlah fotosintat yang dihasilkan. Fotosintat yang dihasilkan memicu pembentukan bunga dan buah yang pada akhirnya berpengaruh terhadap jumlah buah cabai. Sutedjo (2005) ketersediaan unsur hara $\mathrm{N}, \mathrm{P}$ dan $\mathrm{K}$ yang banyak dapat mempercepat pembungaan dan pembentukan buah.

Perlakuan beberapa media tanam Inceptisol meningkatkan jumlah buah cabai per tanaman nyata lebih banyak dibandingkan dengan tanah lainnya, berbeda tidak nyata dengan tanah gambut dan gambut+Inceptisol. Hal ini karenakan unsur P-tersedia pada tanah Inceptisol sebesar 90,77 ppm dan tanah gambut+Inceptisol 60,58 ppm dan tanah gambut memiliki bahan organik yang lebih tinggi sehingga unsur hara dalam tanah meningkat ketersediannya yang berperan dalam proses fotosintesis menghasilkan fotosintat dan didistribusikan kebagian sink yaitu tunas yang sedang tumbuh, sehingga tanaman tumbuh baik, pertumbuhan generatif menjadi lebih optimal sehingga buah meningkat. Winaya (1983) tanah Inceptisol dan gambut memiliki kandungan bahan 
organik (C-organik), P-tersedia pada tanah Inceptisol lebih tinggi untuk pertumbuhan tanaman, mempercepat pembentukan biji dan mendorong pertumbuhan akar dengan cepat.

Perlakuan (Tabel 4) kapur 1,0 x Al-dd menghasilkan jumlah buah cabai per tanaman dengan capaian 36,97 buah, nyata lebih banyak dari dosis kapur $0,0 \times \mathrm{Al}$-dd, berbeda tidak nyata dengan kapur 2,0 x Al-dd. Hal ini menunjukkan bahwa kapur 1,0 x Al-dd dan 2,0 $\mathrm{x}$ Al-dd merupakan dosis yang sesuai untuk meningkatkan $\mathrm{pH}$ dibandingkan dengan tanpa kapur $(0,0 \times$ Al-dd $)$ dimana pada perlakuan $0,0 \times$ Al-dd ini kurangnya ketersediaan hara bagi tanaman, karena $\mathrm{pH}$ tanah rendah (tanah masam), sehingga menyebabkan defisiensi $\mathrm{P}$ karena terfiksasi oleh $\mathrm{Al}$ dan $\mathrm{Fe}$ yang menjadikan proses metabolisme tanaman terutama keberlangsungan fotosintat akan terganggu, sehingga jumlah buah yang dihasilkan lebih sedikit. Harjowigeno (2007) produksi dan pertumbuhan tanaman akan sempurna apabila unsur hara yang diperlukan tersedia dalam jumlah cukup.

\section{Panjang buah}

Hasil pengamatan umur muncul bunga pertama tanaman cabai dapat dilihat pada Tabel 5.

Tabel 5. Rerata panjang buah cabai merah $(\mathrm{cm})$ pada perlakuan pemberian kapur dan berbagai media tanam

\begin{tabular}{lllll}
\hline \multirow{2}{*}{ Media Tanam } & \multicolumn{2}{c}{ Pemberian Kapur pada Medium Kriteria Masam- } \\
& \multicolumn{3}{c}{ Agak Masam } \\
\cline { 2 - 4 } & $\begin{array}{l}0,0 \times \mathrm{Al}-\mathrm{dd} \\
\text { (Kontrol) }\end{array}$ & $1,0 \times \mathrm{Al}$-dd & $2,0 \times \mathrm{Al}$-dd & Rerata \\
\hline Ultisol & $11,20 \mathrm{~cd}$ & $11,51 \mathrm{bcd}$ & $11,94 \mathrm{abc}$ & $11,55 \mathrm{~b}$ \\
Inceptisol & $11,76 \mathrm{abcd}$ & $12,52 \mathrm{a}$ & $12,17 \mathrm{ab}$ & $12,15 \mathrm{a}$ \\
Gambut & $11,85 \mathrm{abcd}$ & $11,98 \mathrm{ab}$ & $11,99 \mathrm{ab}$ & $11,94 \mathrm{ab}$ \\
Gambut+Ultisol & $11,14 \mathrm{~d}$ & $12,07 \mathrm{ab}$ & $12,16 \mathrm{ab}$ & $11,79 \mathrm{ab}$ \\
Gambut+Inceptisol & $11,67 \mathrm{bcd}$ & $12,09 \mathrm{ab}$ & $12,09 \mathrm{ab}$ & $11,95 \mathrm{ab}$ \\
\hline Rerata & $11,52 \mathrm{~b}$ & $12,03 \mathrm{a}$ & $12,07 \mathrm{a}$ & \\
\hline
\end{tabular}

Angka-angka pada baris dan kolom yang diikuti huruf kecil yang sama berbeda tidak nyata menurut uji DNMRT pada taraf $5 \%$

Tabel 5 menunjukkan bahwa pemberian kapur 1,0 x Al-dd pada tanah Inceptisol menghasilkan panjang buah nyata lebih pajang dibandingkan dengan perlakuan kapur $(0,0 \mathrm{x}$ Al-dd dan 1,0 x Al-dd) pada tanah Ultisol, gambut+Ultisol dan gambut+Inceptisol, 0,0 x Al-dd pada tanah Ultisol dan gambut, berbeda tidak nyata dengan perlakuan lainnya. Hal ini karena ketersediaan hara $\mathrm{P}$ sangat rendah dan $\mathrm{pH}$ rendah atau sangat masam, sehingga kurangnya ketersediaan hara bagi tanaman seperti unsur hara $\mathrm{P}$ tidak tersedia sehingga terjadi defisiensi fosfat karena terfiksasi oleh $\mathrm{Al}$ dan $\mathrm{Fe}$ maka tanaman tidak mudah menyerap unsur hara proses fisiologis menjadi tidak berjalan lancar dan ukuran buah menjadi lebih pendek. Hal ini sesuai Tan (1992) semakin rendah $\mathrm{pH}$ tanah maka semakin besar konsentrasi $\mathrm{Al}$, dan $\mathrm{Fe}$ yang dapat larut, sehingga akan semakin besar pula jumlah fosfor yang diikatnya.

Perlakuan media tanam tanah Inceptisol ternyata diperoleh panjang buah nyata lebih panjang dibanding perlakuan Ultisol, meskipun berbeda tidak nyata dengan gambut, gambut+Ultisol, dan gambut+Inceptisol. Hal ini karena unsur hara P-tersedia pada tanah Inceptisol sangat tinggi sedangkan Ultisol sangat rendah. $\mathrm{P}$ mempunyai peranan dalam memicu perkembangan buah. Unsur $P$ merupakan bagian yang essensial dalam proses fotosintesis. Sutedjo (2005) jumlah unsur hara yang diserap tanaman apabila tercukupi, maka proses perkembangan baik fase generatif.

Hasil pengamatan panjang buah pada perlakuan perbedaan dosis pemberian kapur (Tabel 5) menunjukkan bahwa pemberian kapur 2,0 x Al-dd nyata menghasilkan panjang buah cabai dengan capaian 12,07 $\mathrm{cm}$ lebih panjang dari perlakuan dosis $0,0 \times \mathrm{x}$ Al-dd berbeda tidak nyata dengan pemberian kapur 1,0 x Al-dd. Hal ini karena penambahan kapur $1,0 \times \mathrm{Al}$-dd dan 2,0 x Al-dd yang diberikan dapat memperbaiki karakter tanah, diantaranya adalah meningkatkan ketersediaan hara dalam tanah terutama unsur $\mathrm{P}$. Tersedianya unsur $\mathrm{P}$ menyebabkan fotosintat yang dialokasikan kebuah menjadi banyak, sehingga ukuran buah menjadi lebih panjang. Indraganada (1986) $\mathrm{P}$ berperan pada pendewasaan tanaman, mempercepat pembungaan dan pemasakan buah serta biji. 


\section{Diameter buah}

Hasil pengamatan diameter buah tanaman cabai dapat dilihat pada Tabel 6. Tabel 6 menunjukkan bahwa kapur 0,0 x Al-dd pada tanah Inceptisol dan pemberian kapur 1,0 $\mathrm{x}$ Al-dd pada tanah gambut+Inceptisol menghasilkan nyata lebih besar diameter buah cabai merah dari perlakuan lainnya. Hal ini karena kapur 0,0 x Al-dd pada tanah Inceptisol dan kapur 1,0 x Al-dd pada tanah
gambut+Inceptisol memiliki ketersediaan hara P sangat tinggi, sehingga metabolisme tanaman dapat berjalan dengan lancar dalam proses fotosintesis menghasilkan fotosintat yang dapat didistribusikan untuk pertumbuhan generatif dalam pembentukan bunga dan buah. Safuan dan Bahrun (2012) pertumbuhan dan produksi tanaman ditentukan oleh fotosintesis yang dikendalikan unsur hara.

Tabel 6. Rerata diameter buah cabai merah $(\mathrm{mm})$ pada perlakuan pemberian kapur dan berbagai media tanam

\begin{tabular}{lllll}
\hline \multirow{2}{*}{ Media Tanam } & \multicolumn{3}{c}{ Pemberian Kapur pada Medium Kriteria Masam- } \\
& \multicolumn{3}{c}{ Agak Masam } & \multirow{2}{*}{ Rerata } \\
\cline { 2 - 4 } & $\begin{array}{l}0,0 \times \mathrm{Al}-\mathrm{dd} \\
\text { Kontrol) }\end{array}$ & $1,0 \times$ Al-dd & $2,0 \times \mathrm{Al}$-dd & \\
\hline Ultisol & $6,66 \mathrm{ab}$ & $7,06 \mathrm{ab}$ & $6,46 \mathrm{ab}$ & $\mathrm{a}$ \\
Inceptisol & $7,66 \mathrm{a}$ & $6,95 \mathrm{ab}$ & $6,07 \mathrm{ab}$ & $6,89 \mathrm{a}$ \\
Gambut & $6,50 \mathrm{ab}$ & $7,38 \mathrm{ab}$ & $6,03 \mathrm{ab}$ & $6,64 \mathrm{a}$ \\
Gambut+Ultisol & $7,49 \mathrm{ab}$ & $6,66 \mathrm{ab}$ & $6,87 \mathrm{ab}$ & $7,01 \mathrm{a}$ \\
Gambut+Inceptisol & $6,21 \mathrm{ab}$ & $7,64 \mathrm{a}$ & $5,74 \mathrm{~b}$ & $6,53 \mathrm{a}$ \\
\hline Rerata & $6,61 \mathrm{a}$ & $6,76 \mathrm{a}$ & $6,90 \mathrm{a}$ & \\
\hline
\end{tabular}

\begin{tabular}{lccc}
\hline Rerata & $6,61 \mathrm{a}$ & $6,76 \mathrm{a}$ & $6,90 \mathrm{a}$ \\
\hline Angka-angka pada baris dan kolom yang diikuti huruf kecil yang sama berbeda tidak nyata menurut uji DNMRT pada taraf
\end{tabular} $5 \%$

Pada perlakuan media tanam tanah gambut+Ultisol cenderung menghasilkan diameter buah terbesar dengan capaian 7,01 $\mathrm{mm}$, berbeda tidak nyata dengan perlakuan lainnya. Hal ini karena tanah gambut memiliki bahan organik yang tinggi, sedangkan Ultisol memiliki kandungan bahan organik yang rendah sehingga apabila tanah Ultisol ditambahkan gambut maka akan meningkatkan kesuburan tanah, melalui peningkatan perbaikan sifat fisik, kimia dan biologi tanah, selanjutnya memperbaiki tingkat ketersediaan unsur hara di dalam tanah sehingga proses fisiologis tanaman akan berjalan dengan lancar. Agus dan Subiksa (2008) gambut merupakan tanah yang kaya bahan organik karena terbentuk dari sisa tanaman yang belum melapuk sempurna.

Hasil pengamatan perlakuan pemberian kapur (Tabel 6) menunjukkan bahwa kapur 0,0 x Al-dd, 1,0 x Al-dd dan 2,0 x Al-dd tidak memberikan pengaruh terhadap diameter buah tanaman cabai. Hal ini karena masamnya kandungan $\mathrm{pH}$ sehingga ketersediaan hara pada tanah berkurang yang menyebabkan proses metabolisme tanaman tidak berjalan dengan lancar, fotosintesis menjadi terhambat untuk pertumbuhan generatif dalam pembentukan buah. Hakim et al. (1983) pH tanah mempunyai pengaruh yang kuat pada ketersediaan unsur hara. Peningkatan $\mathrm{pH}$ tanah juga akan terjadi apabila kapur yang ditambahkan telah mencukupi kebutuhan tanaman.

\section{Berat buah per tanaman}

Hasil pengamatan diameter buah tanaman cabai dapat dilihat pada Tabel 7 . Tabel 7 menunjukkan bahwa perlakuan kapur 1,0 x Al-dd pada tanah gambut dengan Inceptisol diperoleh berat buah pertanaman lebih tinggi, berbeda tidak nyata dengan perlakuan lainnya, kecuali dengan 0,0 x Al-dd dan 1,0 x Al-dd pada Ultisol dan kapur 1,0 x Al-dd pada Inceptisol. Berdasarkan parameter tersebut pemberian kapur 1,0 x Al-dd pada tanah gambut dengan Inceptisol terjadi peningkatan berat buah sebesar 91,63\% dibanding kapur 1,0 x Al-dd pada tanah Ultisol dan sebesar 90,28\% dibanding perlakuan $0,0 \mathrm{x}$ Al-dd pada tanah Inceptisol.

Hal ini karena pemberian kapur 1,0 x Aldd pada gambut memiliki kandungan bahan organik yang tinggi sehingga apabila dicampur dengan Inceptisol akan terjadi perubahan sifat fisik tanah yang dapat meningkatkan ketersediaan hara dalam tanah, sehingga ketersediaan hara menjadi baik maka fotosintat yang dihasilkan lebih banyak dan disimpan sebagai cadangan makanan terutama pada bagian buah, sehingga berat buah menjadi lebih berat termasuk diameter buah dan jumlah buah. Bernardinus (2002) semakin banyak 
jumlah buah yang terbentuk maka berat buah

yang dihasilkan akan semakin tinggi.

Tabel 7. Rerata berat buah per tanaman cabai merah (g) pada perlakuan pemberian kapur dan berbagai media tanam setelah ditransformasikan

\begin{tabular}{lllll}
\hline \multirow{2}{*}{ Media Tanam } & \multicolumn{3}{c}{ Pemberian Kapur pada Medium Kriteria Masam- } \\
& \multicolumn{3}{c}{ Agak Masam } \\
\cline { 2 - 4 } & $\begin{array}{l}0,0 \times \mathrm{Al}-\mathrm{dd} \\
\text { (Kontrol) }\end{array}$ & $1,0 \times \mathrm{Al}-\mathrm{dd}$ & $2,0 \times \mathrm{Al}-\mathrm{dd}$ & \multirow{2}{*}{ Rerata } \\
\hline Ultisol & $77,27 \mathrm{~b}$ & $70,50 \mathrm{~b}$ & $104,75 \mathrm{ab}$ & $84,17 \mathrm{a}$ \\
Inceptisol & $71,00 \mathrm{~b}$ & $99,17 \mathrm{ab}$ & $104,27 \mathrm{ab}$ & $91,81 \mathrm{a}$ \\
Gambut & $96,82 \mathrm{ab}$ & $102,67 \mathrm{ab}$ & $102,83 \mathrm{ab}$ & $100,77 \mathrm{a}$ \\
Gambut+Ultisol & $101,03 \mathrm{ab}$ & $108,47 \mathrm{ab}$ & $108,42 \mathrm{ab}$ & $110,08 \mathrm{a}$ \\
Gambut+Inceptisol & $82,38 \mathrm{ab}$ & $135,10 \mathrm{a}$ & $112,75 \mathrm{ab}$ & $105,97 \mathrm{a}$ \\
\hline Rerata & $85,90 \mathrm{a}$ & $103,18 \mathrm{a}$ & $106,60 \mathrm{a}$ & \\
\hline
\end{tabular}

Angka-angka pada baris dan kolom yang diikuti huruf kecil yang sama berbeda tidak nyata menurut uji DNMRT pada taraf $5 \%$.

$\begin{array}{llr}\text { Media } & \text { tanam (Tabel 7) } & \text { dapat dilihat } \\ \text { bahwa } & \text { gambut+Ultisol } & \text { cenderung }\end{array}$ menghasilkan rata-rata berat buah lebih tinggi, kemudian diikuti oleh perlakuan cgambut+Inceptisol. Hal ini karena tanah gambut memiliki bahan organik yang tinggi, tanah Inceptisol memiliki unsur hara P-tersedia sangat tinggi mencapai 90,77 ppm dan tanah gambut apabila dicampur dengan tanah mineral (Ultisol, Inceptisol) akan menyebabkan perubahan struktur tanah menjadi lebih gembur sehingga tanah yang gembur akan tercukupi ketersediaan haranya, perkembangkan akar menjadi lebih baik dan daya serap nutrisi oleh akar semaikn membaik. Ketersediaan hara yang cukup dan lengkap selama masa pertumbuhan dan perkembangan tanaman akan mempengaruhi produksi tanaman. Hal ini berkaitan erat dengan fungsi unsur hara yang terlibat dalam proses metabolik dan fisiologis tanaman khususnya fotosintesis, pada proses fotosintesis akan dihasilkan fotosintat sebagai sumber energi dan bahan pembentuk senyawa yang dibutuhkan tanaman dalam perkembangannya. Sebagian besar fotosintat yang dihasilkan akan disimpan dalam organ tanaman seperti akar, batang, daun, buah dan biji yang merupakan bentuk produk hasil tanaman. Dwidjoseputro (1998) tanah yang berstruktur remah sangat baik untuk pertumbuhan dan perkembangan tanaman, karena di dalamnya mengandung bahan organik yang merupakan sumber ketersediaan hara bagi tanaman.

Penggunaan kapur menunjukkan bahwa dosis 2,0 x Al-dd cenderung menunjukkan berat buah tertinggi, berbeda tidak nyata dengan pemberian kapur 0,0 x Al-dd dan 1,0 x Al-dd. Hal ini karena penambahan kapur yang diberikan mampu meningkatkan $\mathrm{pH}$ sehingga kondisi tanah menjadi baik bagi perkembangan mikroorganisme tanah, jika tanah tersebut mengandung bahan organik sebagai sumber energi bagi mikroorganisme. Menurut Budi dan Sari (2015) peningkatan $\mathrm{pH}$ akibat kapur menciptakan kondisi yang lebih baik bagi kehidupan mikroorganisme didalam tanah.

\section{KESIMPULAN DAN SARAN}

\section{Kesimpulan}

1. Perlakuan pemberian kapur $1,0 \times \mathrm{x}$ Al-dd dan pengguaan media tanam Inceptisol memberikan pengaruh baik terhadap parameter tinggi dikotomus, diameter batang, jumlah buah, panjang buah, diameter buah dan berat buah pada tanaman cabai merah

2. Penggunaan pemberian kapur $1,0 \mathrm{x}$ Al-dd pada media tanam gambut+Inceptisol berpengaruh baik terhadap pertumbuhan dan hasil diameter batang, umur bunga, jumlah buah, panjang buah, diameter buah dan berat buah tanaman cabai merah. Pemberian kapur 1,0 x Al-dd pada gambut+Inceptisol menghasilkan produktivitas sebesar $135,10 \mathrm{~g}$ per tanaman.

\section{Saran}

Berdasarkan hasil penelitian yang telah dilakukan untuk pertumbuhan dan produksi tanaman cabai merah Varietas Lado F1 yang baik disarankan menggunakan media tanam gambut+Inceptisol dengan pemberian kapur $1,0 \times \mathrm{Al}-\mathrm{dd}$. 


\section{DAFTAR PUSTAKA}

Agus, F dan I. G. M. Subika. 2008. Lahan Gambut, potensi untuk Pertanian dan Aspek Lingkungan. Balai Penelitian Tanah dan World Agroforestry Center (ICRAF). Bogor.

Badan Pusat Statistik. 2017. Produksi Cabai Besar dan Cabai Rawit di Riau. www.bps.go.id. Diakses pada tanggal 22 September 2017.

Bernardinus, $\mathrm{T}$ dan W. Wiryanta. 2002. Bertanam Tomat. Agromedia Pustaka. Jakarta.

Damanik, M. M. B., B. E. Hasibuan., Fauzi., Sarifuddin dan H. Hanum. 2010. Kesuburan Tanah dan Pemupukan. Usu Press. Medan.

Doberman, A and T. Fairhurst. 2000. Rice, nutrient disorders and nutrient management. IRRI. Mekati City. The Philippines.

Dwidjoseputro. $1998 . \quad$ Dasar-Dasar Mikrobiologi. Penerbit Djambatan. Jakarta.

Hakim N. 1983. Pengapuran adalah suatu teknologi tepat guna untuk meningkatkan produksi pangan di pedesaan. Seminar IPTEK. Semarang. 24-28 Juni 1983. 12-13.

Hanafiah, K.A. 2013. Dasar-Dasar Ilmu Tanah. Rajawali Pers.

Jakarta.

Hardjowigeno, S. 2007. Klasifikasi Tanah dan Pedogenesis. Akademika Pressindo. Jakarta.

Indraganada, H. K. 1986. Pengolahan Kesuburan Tanah. Bina Aksara. Jakarta.

Kasno, A. 2009. Respon Tanaman jagung terhadap pemupukan fosfor pada typic dy trudepts. Jurnal Tanah Tropika. 14(2): 111-118.

Koesrini., K. Anwar dan E. Berlian. 2015. Penggunaan Kapur dan Varietas Adaftif Untuk Meningkatkan Hasil Kedelai di Lahan Sulfat Masam Aktual. Jurnal Berita Biologi. 14(12): 155-161.

Lakitan B, 2011. Dasar-dasar Fisiologi Tanaman. Raja Grafindo Persada. Jakarta.

Poerwanto, R. 2003. Budidaya Buah-buahan: Proses Pembungaan dan Pembuhaan. Bahan Kuliah. Fakultas Pertanian, IPB. Bogor.
Prasetyo, T. B. 1996. Perilaku Asam-Asam Organik Meracun pada Tanah Gambut yang Diberi Garam Na dan Beberapa Unsur Mikro $\mathrm{Cu}$ dalam Kaitannya dengan Hasil Padi. Disertasi (Tidak dipublikasikan). PPS IPB. Bogor.

Rosmarkam, A. dan N.W. Yuwono. 2002. Ilmu Kesuburan Tanah. Kanisius. Yogyakarta.

Safuan, L. O dan A. Bahrun (2012). Pengaruh bahan organik dan pupuk kalium terhadap pertumbuhan dan produksi tanaman melon (Cucumis melo L.). Jurnal Agroteknos. 2(2): 69-76.

Soepardi, G. 1990. Mengelola Lahan yang Tanahnya Berkendala Reaksi Masam. Seminar Nasional. Planta Gama, tanggal 27 Oktober 1990. Yogyakarta.

Suharta, N. 2010. Karakteristik dan permasalahan tanah marginal dari batuan sedimen masam di kalimantan. Jurnal Litbang Pertanian. Bogor. 29(4): 139-146.

Sukristiyonubowo., Mulyadi., P. Wigena dan A. Kasno. 1993. Pengaruh Penambahan Bahan Organik, Kapur, dan Pupuk NPK terhadap Sifat Kimia Tanah dan Hasil Kacang Tanah. Pemberitaan Penelitian Tanah dan Pupuk. Bogor. 11(2):1-7.

Sutedjo, M. M. dan A. G. Kartasapoetra. 2002. Pengantar Ilmu Tanah, Terbentuknya Tanah dan Tanah Pertanian. Rineka Cipta. Jakarta

Suwardi. 2007. Pemanfaatan zeoilit untuk perbaikan sifat-sifat tanah dan peningkatan produksi Pertanian. Dipresentasikan pada Semiloka Pembenah Tanah Menghemat Pupuk, Mendukung Peningkatan Produksi Beras. Direktorat Jenderal Pengelolaan Lahan dan Air, Departemen Pertanian Bekerjasama dengan Konsorsium Pembenah Tanah Indonesia. Jakarta, 5 April 2007

Tan, K. H. 1995. Dasar-dasar kimia tanah. UGM Press. Yogyakarta.

Winaya, D. 1983. Kesuburan Tanah dan Pemupukan. Jurusan Tanah Fakultas Pertanian. Universitas Udayana. Bali.

Wiryanta, W. T. 2011. Panduan Lengkap Budidaya dan Bisnis Cabai. PT. Agromedia. Jakarta. 
